\title{
ESTUDIO PILOTO: UNA APROXIMACIÓN CUALITATIVA A LA FibROMIALGIA DESDE LA PERSPECTIVA DE GÉNERO
}

\author{
Erica Briones Vozmediano \\ Universidad de Alicante \\ erica.briones@ua.es
}

Recibido: $28-02-2010$

Aceptado: 31-03-2010

Resumen: La Fibromialgia es una enfermedad que afecta principalmente a las mujeres y cuya etiología permanece desconocida. Se parte de la concepción de que las desigualdades de género pueden ser determinantes de las diferencias en salud. El presente estudio piloto pretende ofrecer una primera aproximación a la comprensión de la enfermedad de fibromialgia desde un enfoque de género, que explora tanto las causas como las consecuencias en la calidad de vida de las pacientes. Para ello, se han efectuado cuatro entrevistas en profundidad a mujeres afectadas de fibromialgia residentes en la provincia de Alicante (España).

Palabras clave: fibromialgia, género, salud, mujeres, roles.

\begin{abstract}
Fibromyalgia is a disease that affects mainly women, of which etiology remains unknown. We start from the idea that gender inequalities can be determinant of differences in health. The present pilot study aims to provide a first approximation into the understanding of the fibromyalgia disease, from a gender perspective, that explores both the causes and the consequences on the quality of life of female patients. To this end, we carried out four indepth interviews with women diagnosed with fibromyalgia who live in Alicante (Spain).
\end{abstract}

Key words: Fibromyalgia, gender, health, women, roles. 


\section{Introducción}

La Fibromialgia (FM) es una enfermedad que afecta prácticamente en exclusiva a mujeres. La Sociedad Española de Reumatología otorga una prevalencia de 2,4\%, con un ratio hombre/mujer de 1:20 (Rivera, 2006). Debido a su alta prevalencia, se considera que es de gran trascendencia en la salud pública (Valls Llobet, 2007).

La etiología de este padecimiento es todavía desconocida, no existen pruebas objetivas que determinen su causa pero, aún así, se reconoce la importancia de los factores psicosociales que pueden estar implicados en la aparición y/o persistencia de la enfermedad.

Se parte de una concepción biopsicosocial del proceso de salud/enfermedad, que tiene muy en cuenta la influencia del contexto social en la salud. Las diferencias en salud no sólo se explican por causas biológicas, si no que están también determinadas por el contexto sociocultural y las condiciones de vida diferenciales entre hombres y mujeres. Las diferencias de género, que tienen su punto de partida en las diferencias basadas en sexo, desembocan en una situación de desigualdad en la vida diaria que condiciona, entre otras muchas cosas, la salud de las personas.

El presente estudio pretende ser una aproximación a la comprensión de la enfermedad de FM desde la perspectiva de género, que ahonda tanto en las causas como en las consecuencias en la calidad de vida de las pacientes. En este sentido, continuar la línea de investigación que explora la relación entre género y FM (Paterna Bleda et al., 2003a).

\section{Antecedentes}

La producción teórica sobre la FM y su relación con factores relacionados con el género en el ámbito de habla hispana (España y América Latina) es aún escasa. En concreto, los antecedentes que tienen que ver con la socialización diferencial de género, las variables relacionadas con las experiencias de vida previas al desarrollo de la FM y las consecuencias de la asunción del rol de género en la salud de las mujeres. 
La FM ha sido bastante estudiada desde la perspectiva biologicista, por la reumatología y el campo médico en general, pero son minoritarias las investigaciones que aborden el fenómeno desde una perspectiva multidisciplinar, que integre los determinantes socioculturales de la salud en el análisis de la enfermedad de FM. Desde las ciencias humanas y sociales, el abordaje de este fenómeno ha sido mayoritariamente psicológico. Además, los estudios que abordan las posibles causas sobre la mayor prevalencia de la enfermedad en mujeres son prácticamente inexistentes y apenas hay trabajos cualitativos sobre su historia biográfica, sino que predominan los estudios cuantitativos.

Por tanto, la mayor prevalencia de la FM en las mujeres todavía está pendiente de estudio, tal y como evidencia que hasta la fecha sean escasos los trabajos que analizan diferencias de género en este síndrome. Sobre todo, se han abordado aspectos como diferencias en la presentación y gravedad de algunos síntomas entre hombres y mujeres y diferencias en la calidad de vida (Ruiz Pérez et al., 2007; Muro Gaztañaga, 2007; Mingote Adán, 2000). Pero al no hallarse marcadores orgánicos concretos que expliquen biomédicamente el cuadro de síntomas, se hace necesario considerar los factores individuales y subjetivos.

Pocos trabajos abordan los antecedentes de carácter psicosocial relacionado con los factores de género en el contexto del síndrome de FM. La mayoría de estos estudios han hallado que una historia de vida traumática es una variable importante de análisis en el estudio de la FM, como por ejemplo ser víctima de violencia de género (Ubago Linares et al., 2005; Ruiz Pérez et al., 2008; Cantera Espinosa, 2004; Blanco et al., 2004). Mientras que aún son pocos los trabajos que estudian directamente los roles de género, el conflicto de roles, el estrés y la identidad social de género como antecedentes relacionados con la FM (Aparicio, 2002; González de Chávez, 2002; Tosal Herrero, 2007; Valls Llobet, 2002, 2006 y 2007).

La conclusión general de estas investigaciones se dirige a afirmar que todavía son escasos los estudios que analicen las diferencias de género en la FM, por lo que se hace necesario continuar con esta línea de investigación debido a la mayor prevalencia de las mujeres y la falta de una explicación biomédica. 
Se trata de una línea de investigación reciente, prácticamente inexistente en el panorama de habla hispana, si bien no mucho más extensa internacionalmente tal y como concluyen los estudios de revisión en este sentido (Paterna Bleda et al., 2003a; Paterna Bleda et al., 2003b; Velasco et al., 2006).

\section{Metodología}

Se ha llevado a cabo un estudio piloto basado en la realización de cuatro entrevistas en profundidad a mujeres diagnosticadas de FM, residentes en la provincia de Alicante, con la finalidad de obtener información sobre sus experiencias y las implicaciones de la FM en su rutina diaria y en sus relaciones familiares, desde un enfoque de género. Del registro de las variables prioritarias han quedado definidas las siguientes categorías muestrales:

Cuadro 1. Datos sociodemográficos de las mujeres entrevistadas

\begin{tabular}{|c|c|c|c|c|}
\hline $\begin{array}{c}\text { Código } \\
\text { entrevista }\end{array}$ & Edad & Localidad & $\begin{array}{c}\text { Estado civil y } \\
\text { número de hijos/as }\end{array}$ & Ocupación \\
\hline EAF01 & 59 años & Alicante & $\begin{array}{c}\text { Casada. 2 hijos } \\
\text { varones. }\end{array}$ & $\begin{array}{c}\text { Hace cuatro años se le concedió la } \\
\text { incapacidad laboral permanente. } \\
\text { Antes era secretaria y celadora en un } \\
\text { hospital -pluriempleada-. }\end{array}$ \\
\hline EAF02 & 55 años & $\begin{array}{c}\text { Petrer } \\
\text { (Alicante) }\end{array}$ & $\begin{array}{c}\text { Casada. 2 hijos } \\
\text { varones. }\end{array}$ & $\begin{array}{c}\text { Está en paro, antes trabajaba en una } \\
\text { empresa familiar (fábrica de } \\
\text { calzado). }\end{array}$ \\
\hline EAF03 & 51 años & $\begin{array}{c}\text { Elche } \\
\text { (Alicante) }\end{array}$ & $\begin{array}{c}\text { Casada. 2 hijas y 1 } \\
\text { hijo. }\end{array}$ & $\begin{array}{c}\text { No trabaja, anteriormente su } \\
\text { ocupación principal era trabajadora } \\
\text { en fábrica de calzado. }\end{array}$ \\
\hline EAF04 & 25 años & $\begin{array}{c}\text { Elda } \\
\text { (Alicante) }\end{array}$ & $\begin{array}{c}\text { Soltera y sin } \\
\text { hijos/as. }\end{array}$ & $\begin{array}{c}\text { Trabaja algunos fines de semana en } \\
\text { un pub nocturno poniendo música. } \\
\text { Antes trabajaba en hostelería. }\end{array}$ \\
\hline
\end{tabular}

Fuente: elaboración propia 
El objetivo general de la investigación es explorar la relación existente entre el síndrome de FM y los rasgos asociados al género para comprobar cómo la desigualdad de género repercute en el impacto diferencial de esta enfermedad, en cuanto a prevalencia, morbilidad y consecuencias para la calidad de vida.

Los objetivos específicos que se pretenden explorar a través de las entrevistas son: indagar en la relación entre la sobrecarga derivada del rol de género y el proceso salud/enfermedad; recoger las reflexiones de mujeres afectadas sobre diversos temas relacionados con su enfermedad, como las consecuencias de la FM en su calidad de vida, las limitaciones derivadas de la FM en el desarrollo de su vida diaria y los antecedentes vitales; identificar las principales dificultades derivadas de la enfermedad que sufren las mujeres en cuanto a cumplimiento de responsabilidades familiares y averiguar de qué manera las mujeres entrevistadas experimentan su desarrollo; explorar los antecedentes vitales de las afectadas, en especial referentes a la conciliación entre el ámbito laboral y el familiar; identificar los factores derivados de la interiorización de la identidad de género y sus consecuencias en cuanto a cumplimiento de las expectativas de género (ideal de género, maternidad, socialización para el cuidado); y explorar la relación entre malestar físico y psicológico.

La hipótesis de partida es que la desproporcionada prevalencia de la FM puede estar relacionada con la sobrecarga sufrida por muchas mujeres debido al modo de vida actual occidental, en el que se ven expuestas a múltiples demandas impuestas por su condición de mujer, en concreto la doble jornada y las condiciones estresantes que de ello se derivan. Es decir, la sobrecarga de las mujeres por una rígida adscripción a los roles de género podría manifestarse a través de dolencias y síntomas característicos de la FM.

Las hipótesis derivadas son que: la incorporación de la mujer al trabajo no ha producido un cambio en la mentalidad de los hombres, ni en la de muchas mujeres, puesto que las mujeres siguen haciendo tres veces más trabajo en casa que el que hacen los hombres; los factores externos que implican un sobreesfuerzo y una carga, así como el estrés vivido por las mujeres por tener que cumplir todos los papeles sociales (esposa, 
madre, trabajadora, cuidadora, amiga, hija...), sino explicar la etiopatogenia, pueden agravar la experiencia de la enfermedad; las expectativas de género son más rígidas para las mujeres que para los hombres, y el cumplimiento del ideal de género (rol de cuidado, perfección, superwoman, idealización de la maternidad, belleza) puede generar conflictos psíquicos en las mujeres, como frustración, sentimientos de culpa o malestar emocional. Estos, a su vez, podrían tener su expresión en el cuerpo a través de malestar físico y síntomas corporales.

Respecto a la temporalización del estudio, éste se ha estructurado en tres fases comprendidas de mayo a septiembre de 2009: a) revisión bibliográfica b) realización del trabajo de campo (realización de las entrevistas) y c) transcripción, clasificación, análisis y redacción de los resultados.

\section{Principales resultados e implicaciones}

Los resultados se han estructurado en tres aspectos: el perfil de las mujeres afectadas de FM, antecedentes y limitaciones en el ámbito privado: el desarrollo de las tareas del hogar, y en el ámbito público: el desarrollo de un trabajo remunerado.

\subsection{El perfil de las afectadas de FM}

Las mujeres entrevistadas se describen mediante los rasgos de perfeccionismo, autoexigencia y responsabilidad, que aunque no implican necesariamente una predisposición a la FM, al menos podrían considerarse como un factor de riesgo. Por ejemplo, el afán por la limpieza es algo habitual entre las mujeres y hunde sus raíces en la socialización de género, que las educa para "ser buenas amas de casa" pero puede acabar derivando en una obsesión que, indiscutiblemente, genera malestar en estas mujeres. 
"Y luego, estuve una temporada cuando estuve trabajando que eran las dos crías pequeñas, que estaba obsesionada con limpiar. El hecho de que tenía poco tiempo, tenía poco tiempo porque trabajaba 11 horas todos los días, pues bueno como eran jornadas partidas, pues... el fin de semana me obsesionaba limpiar, limpiar, limpiar, hasta que mi marido se enfadó conmigo y dice "no, esto está limpio, no hay que limpiar, y nos vamos con las crías y te olvidas y tal” (EAF03).

Otro nexo común entre las entrevistadas es el hecho de esconder emociones: todas afirman que no les gusta quejarse ni expresar verbalmente su malestar. No se desahogan con los demás hablando de los problemas derivados de la enfermedad, porque no quieren concentrarse en sus dolores pero también ligado al deseo de no preocupar a los demás y no sentir que son una carga para ellos.

"Y yo luego también he tenido posiblemente el defecto o la eso que tampoco me ha gustado preocupar a nadie y siempre me lo he tragado. Por lo que fuera. Eso sí que lo he tenido toda la vida. Y sigo igual, porque yo ya te digo, viene mi hijo y que mi hijo me diga "mamá ¿cómo estás?", "bien cariño" [...] mi marido decía "tienes que haber estado muy mala para tu decir que mal que me encuentro, porque tu normalmente no..." es que me pregunta "como estás", "bien", y a lo mejor me encuentro mal y yo digo "Bien". Claro vienen mis hijos, a lo mejor vienen a cenar o a comer, nos juntamos “¿Cómo estás mamá?", "bien”. ¿Es que vienen las criaturas y les voy a decir "Me duele aquí, me duele allí, me duele..."? No digo nada" (EAF01).

Por otra parte, el perfil de paciente de FM que se entresaca de las reflexiones de las mujeres entrevistadas no coincide totalmente con el descrito por la literatura científica, que identifica como ejes vertebradores de sus vidas los conflictos personales, sobre todo de pareja, y la insatisfacción personal. Estos aspectos no han aflorado en las 
reflexiones de las entrevistadas, pero en cambio sí en la imagen que éstas tienen de otras enfermas de FM con las que hayan podido tener contacto.

“[...] después estuve en la asociación que no me gustó [...] yo no veía ánimo de lucha, yo no era ese mi objetivo... sus objetivos eran eh...cobrar una paga у... "yo no puedo trabajar, yo no puedo trabajar, y yo no puedo trabajar...” y mi objetivo no era ese. Mi objetivo era luchar para poder mantener mantenerme y para poder estar viviendo con la enfermedad y, y si yo me apuntaba a la asociación era para hacer hincapié en que investigaran, y en que nos comprendieran, no para que nos dieran una paga, ese no era mi objetivo. [...] Y por eso me la dejé. Yo tenía trabajo... y entonces pues ya me la dejé. [...] entonces cuando me fui a la asociación, y la gente que estaba allí estaba con un único objetivo, "ay qué mala que estoy... esto, no puede ser... esto, yo... que mi marido me ha dejado...porque... no puedo vivir... [...] y yo veía esas cosas y me hundía [...]" (EAF02).

De hecho, las mujeres entrevistadas no se sienten identificadas con las asociaciones de enfermas de FM ni pertenecen a ninguna, si bien en ocasiones hicieron un primer acercamiento, pero ante la realidad que observaron en cuanto a las situaciones de las mujeres que sí forman parte de ellas decidieron no involucrarse. Prevalece en ellas la concepción de que las mujeres que acuden a las asociaciones tienen muchos problemas personales, como familiares y de pareja, por lo que ellas mismas no lo necesitan e incluso pueden llegar a sentirse culpables por ello, al compararse con el resto de mujeres de la asociación. Además, existe una especie de temor al contagio de su estado de ánimo negativo, ante la experiencia de haber presenciado algún testimonio vital negativo de las enfermas, quienes en las terapias de grupo se desahogan y comparten su experiencia con el grupo. 
"Si no tienen apoyo, entonces claro van allí y se desahogan. Claro yo veía muchas mujeres que a lo mejor iban y a lo mejor nos juntaban a 4 o 5 y a mí ya me daba hasta un poco de vergüenza, porque nos juntaban a 4 o 5 y a lo mejor una empezaba "ay, es que mi marido no se lo cree, y mis hijos y me dicen que no se qué y me dicen que no sé cuantos..." y yo la miraba y pensaba "bueno que, encima de estar mala... en su casa...", la otra "es que yo, me llevo muy mal con mi marido, o estoy separada de mi marido, no tengo dinero...", claro cada una contaba su problema y hay muchos problemas, que no nos damos cuenta, claro cuando llegaban a mi me decían “¿y tú?” y yo decía “¿y qué quieres que te cuente? Si yo no..." y me daba hasta... mmm no sé cómo explicarte, hasta apuro [...] No me hacía falta, al revés, yo me sentía mal, me sentía mal por todas las compañeras que yo veía que estaban allí que veía que tenían en realidad casi todas problemas, y yo no tenía ningún problema, y me sentía mal” (EAF01).

Otro aspecto a tener en cuenta a la hora de hablar del perfil de las pacientes es el estrato socioeconómico. La muestra entrevistada pertenece a la clase media-baja, lo que viene determinado sobre todo por dos factores: el económico, derivado de la posición laboral, y el educativo. De hecho, tres de las cuatro mujeres entrevistadas coinciden en tener un nivel de estudios básico o tan sólo unos años de escolarización.

Cuando las mujeres afectadas reflexionan en torno a las posibles causas de la enfermedad, sus teorías espontáneas al respecto en ocasiones coinciden con las explicaciones científicas etiopatogénicas al considerar algunos hechos como posibles determinantes del desarrollo de la enfermedad (el estrés, un trauma psicológico o la propia sobrecarga derivada de la doble jornada, entre otros).

"Mira yo... siempre he pensao que el sistema nervioso lo tengo súper trastocao, y a partir de ahí si eso se hace físico, porque eso es lo que se suele decir, se somatiza, son las palabras técnicas yo las he ido aprendiendo a lo largo de haber ido a diferentes sitios... Pues yo creo que es lo que me ha 
pasao, porque ten en cuenta que yo cuando pequeña cuando empecé... soy una persona muy... no he sido muy cariñosa, o sea, he pensao siempre como muy adulto, me... siempre he estao dándole vueltas a las cosas “y esto por qué, por qué no... y por qué...” o sea, cosas que no han sido normales en... para mi edad y esas cosas, entonces yo creo que eso tiene que haber contribuido mucho" (EAF03).

De hecho, la relación entre la FM y el malestar psicológico parece incuestionable: ellas mismas identifican como elemento que empeoran su estado físico algún tipo de malestar emocional, como pueden ser preocupaciones, disgustos o nerviosismo.

"Yo noto por ejemplo que... que pues, voy a tener un estrés, o cosas que pasan de... alguna cosa o familiar o íntima o física o lo que sea, pues digamos que me afecta más. Ahora nosotros este año, en marzo nos despidieron a mi marido y a mí, que fue cuando nos vinimos mi marido y yo de Córdoba, pues quieras que no yo llevaba mucho tiempo sin tener algún ataque y quieras que no voy teniendo alguno" (EAF02).

"A mí me afecta. Y ya te digo, si me pongo nerviosa por lo que sea, yo noto que me afecta, que antes no me afectaba. Hace años, no sé cómo decirte, no es que no me afectara, pero es que yo físicamente ahora me noto eso, que me... como si me... pusiera peor cuando estoy nerviosa. ¿sabes lo que te quiero decir? O sea yo me pongo nerviosa... yo ayer "No ponerme nerviosa ninguno, que luego lo paso mal" es que yo me lo noto luego, es como si estuviera subiendo la escalera y bajara dos escalones. En vez de subir, bajar. - ¿Y QUÉ TE NOTAS?

Me noto cansancio. Y eso... sobre todo cansancio. Dolor... prácticamente me duele pero, pero más que nada es cansancio, o dejadez, no sé cómo explicarte, pero... cansancio. Porque... es que yo reconozco que debo de llevar una vida..." (EAF01). 
“[...] perdí el conocimiento el año pasao, del dolor, y de la ansiedad. Fue un caso de una mujer muy maleducada, bueno una movida que pasó con una vecina [...] y bueno me armó una ahí que te cagas [...] yo no sé qué me pasó que me quedé tiesa y me caí pa'tras" (EAF04).

Es habitual tanto en la literatura científica como en los discursos de las afectadas el hacer alusión a unos determinados antecedentes vitales, que pueden considerarse traumáticos emocionalmente y que se sitúan teóricamente como potenciales antecedentes de FM. De hecho, las mujeres afectadas coinciden en tener una trayectoria vital que tiene algunos rasgos en común. Por ejemplo, un hecho puntual que se ha encontrado de forma reiterada en sus trayectorias vitales es la pérdida de un familiar de forma prematura, lo que, lógicamente, les ha supuesto un trauma emocional y atravesar un proceso de duelo, lo que se ve agravado por la tendencia a esconder las propias emociones.

"Luego mi madre murió muy joven, cuando yo tenía 18, tuvo un cáncer de pecho muy malo, y en aquella época no era como ahora que te ponen cosas y eso ¿sabes lo que te quiero decir?... la quimioterapia y eso... le quitaron un pecho, estuvo dos años hasta morir, luego se le subió a la cabeza... yo lo recuerdo muy mal todo aquello, lo pasé muy mal... estábamos muy unidas" (EAF01).

"El acontecimiento más negativo para mí fue que mi hermana la mayor con 26 años y dos niños, la atropelló un coche y la mató. De esto hace 30 años ya, yo tenía 18 años... eso nos afectó muchísimo, era una persona joven con mucha salud y eso fue algo... fue muy duro, muy duro" (EAF03).

Otros ejemplos son el desarraigo durante la infancia y la frecuencia de que preceda o coincida con la emergencia de la enfermedad un periodo vital en el que se ha estado sometido a una presión añadida a la habitual, que haya generado una crisis vital en las afectadas. 
"En Barcelona y en... he vivido en, en esos diez años he vivido en Barcelona, en el pueblo poquito porque nací y nos fuimos para otra parte, en Castellón en Onda, que mi segundo hermano vive allí, aquí en Elche y luego también estuve viviendo cuando me casé, estuve viviendo un par de años en Murcia, en.... Torres de Cotillas, y ya después me vine otra vez aquí, y ya está” (EAF03).

“Aquí no teníamos a nadie, porque nos vinimos yo pequeña con 10 años, yo nací en Venezuela, mi padre es de Madrid y mi madre de Madrid y claro aquí no teníamos familia, éramos sólo los tres. Y claro nos quedamos mi padre y yo solos" (EAF01).

"Después otra cosa psicológica que... que me pasó fue que fue en aquel momento que se casó mi hijo. Pues yo estaba con lo de la boda... estaba con el proyecto de casarse. /.../ puede ser que yo sin saberlo tuviera miedo porque él, claro él era cuando él se estaba preparando de hecho se casó en mayo y esto me lo diagnosticaron en junio, y en ese momento yo lo estaba pasando muy mal muy mal muy mal, y que tiene relación con esto. Y a partir de ahí es que fue todo seguido" (EAF02).

Preocupaciones que pueden minar la estabilidad emocional suelen aparecer como antecedentes que pueden estar relacionados con la FM, tal y como las propias pacientes parecen relacionar. O, por lo menos, cuando describen las características vitales del tiempo inmediatamente precedente al advenimiento de la enfermedad, en ellas dominan las situaciones estresantes y/o de sobrecarga física.

"Yo muchas veces me notaba muy estresada, yo" (EAF01).

"Pues fue... yo me encontraba muy mal muy mal... muy mal. Y entonces yo notaba... yo cargaba y descargaba, trabajaba cargando y descargando..." (EAF02). 
En cambio, algunas de las afectadas de FM recuerdan haber padecido síntomas que podrían estar asociados a la FM desde la infancia. Está comprobado médica y psicológicamente que las experiencias infantiles pueden derivar en traumas que, a su vez, pueden somatizar en la vida adulta. En este sentido, algunas de ellas reportan conservar recuerdos negativos de la infancia o haber sufrido algún traumatismo físico como un accidente de tráfico (Ortega Pérez, 2004).

"Desde siempre. Y yo recuerdo de mandarme mi... por eso te digo que yo creo que esto lo tenemos toda la vida, porque yo recuerdo de mandarme mi madre a un mandao y encontrarme muy mal muy mal muy mal y tenerme que sentarme en un portal hasta que me he recuperado, y esto sería... un ataque de lo mismo" (EAF02).

"Me lo diagnosticaron porque mmm... yo de pequeña tenia, porque con 7 años tenía estados de ansiedad que era... pero no sé si me los provocaba... porque me asustaba, porque... es que son cosas muy complicadas de, de explicar. Bueno, me pasaba algo raro que yo no entendía y eso hacía que me... y aún me sigue pasando, menos pero aún. Me asustaba, me entraba como ansiedad de pánico de de de, de no saber qué es lo que tenía, lo que pasaba, pues tal [...] En la adolescencia... empecé a notar muchos dolores de espalda, mi madre me llevaba al médico pero decían que era del crecimiento de tal, y entonces por aquel entonces no se hacían, así, radiografías... pero mis dolores de espalda siguieron, junto con lo demás, con otras historias y... y ya llegó un momento en que... ya cogí ansiedad con depresión aparentemente" (EAF03).

“[...] yo es que desde los 14 o 15 años siempre he estado, eso que se te queda el cuello... Pues eso que desde pequeña, bueno 14 o 15 años, que siempre eso que se te queda el cuello enganchao ¡ahh! Tortícolis de esa ¿no? Siempre he sufrido de eso, siempre que cambiaba el tiempo ¡zas! Me quedaba enganchá. Y nada, así hasta los 18 y 19 que estaba trabajando en un supermercado, ya me habían dado varios perchones en la espalda pero bueno no le hacía mucho caso [...]" (EAF04). 


\subsection{Antecedentes y limitaciones en el espacio privado: el desarrollo de las tareas domésticas}

Las mujeres entrevistadas han hecho alusión a las responsabilidades domésticas como una de las principales facetas de la vida que la enfermedad les impide realizar con normalidad. Las mujeres, en general, han asumido este rol debido a que constituye la norma social: la socialización de género moldea a las mujeres desde que son niñas para que asuman aquellas tareas que son adecuadas para ellas, provocando que interioricen la identidad de género vinculada a las responsabilidades familiares. Por ello, muchas de las afectadas de FM tienen tan asumido este rol que no se plantean que pueda ser de otra manera o por qué es así.

"Entonces yo me noto, cuando hago cosas [en casa] se me va, estoy mejor
porque no estoy tan rígida, claro luego me canso mucho, pero yo veo que
puedo hacerlo, el día que yo vea que no puedo pues [...]" (EAF01).

Otro aspecto importante en este sentido es la importancia que le otorgan al orden y la limpieza, y el malestar que genera en ellas el no tener todo "correcto". Se trata de una autoexigencia y perfeccionismo que define el perfil de las mujeres afectadas de FM, como extensión de las características deseables en las mujeres: ordenadas, limpias, que cuiden del hogar y sus miembros, etc.

"Me cuesta muchísimo. Me cuesta un montón, eso de ponerme límites para mí,
es lo que peor llevo ¿eh? Pero tengo limitaciones y... y ya te digo, a veces me
paso. Me paso mucho. Pero me siento bien conmigo y luego me duele todo, digo
"madre mía si estoy... estoy, para tirarme a la basura” pero a la vez estoy a gusto,
no sé como como... es que es una cosa muy contradictoria pero [...]” (EAF03).

Ellas mismas afirman, pero a la vez en la práctica parecen no ser conscientes 
de ello, que su afán de superación acaba siendo perjudicial para su estado físico. Viven como una resignación el tener que bajar las expectativas y asumir sus propias limitaciones que les impiden llevar el ritmo de antes; pero en vez de no hacer tantos esfuerzos, delegar la carga o pedir "ayuda" -una ayuda que no sería concebida como tal si no se considerase este ámbito del hogar como específicamente suyo, femenino-, suelen optar por otras estrategias como la de dedicar más tiempo que antes para hacer la misma cantidad de cosas. Y ante estas limitaciones, las afectadas de FM a veces "no tienen más remedio" que pedir ayuda, algo que parece costarles un esfuerzo personal.

"Hay días que no puedo hacer la cama. Hay días que prefiero hacer una pizza tío...es que no, no puedes hacer las cosas del día a día. Pasear al perro, recoger una caca... hay días que no. Hay días que me toca llamar a alguien "ven aquí y échame una mano porque no puedo" eso es fatal, pues imagínate en el trabajo" (EAF04).

Una estrategia que libera parte de la carga de las tareas del hogar a las mujeres afectadas de FM -como a todas las mujeres que asumen en exclusiva esta tarea, pero a las mujeres que están enfermas en especial- es la externalización del trabajo doméstico, mediante la contratación de una ayuda externa. Y es que el trabajo doméstico sólo adquiere importancia, conciencia de su valor, cuando es desempeñado por alguien ajeno al propio hogar, es decir, las propias mujeres que son quienes asumen este empeño en exclusiva en la mayoría de los casos. Aún así, se trata de una estrategia que sólo libera en parte la carga del hogar.

"Bueno la mujer que me limpiaba era una vez a la semana para limpiar, unas horas para limpiar, y solamente eso, y todo lo demás yo ya [...]” (EAF02).

No obstante, incluso hay quienes se niegan a esta posibilidad aunque económicamente puedan permitírselo puesto que, por parte de las mujeres, esta 
construcción de la feminidad está tan interiorizada que el no cumplimiento de este rol viene a menudo acompañado por un sentimiento de culpa importante. Lo tienen tan asumido como responsabilidad que no conciben que estas tareas puedan ser realizadas por otros, lo han hecho toda la vida y forma parte de su identidad femenina, puesto que de no realizar estas tareas se sentirían como "poco útiles" o les generaría remordimientos al no cumplir sus obligaciones y sentir que "no hacen nada".

"[...] mi marido me dice "ponte una chica", pero yo no quiero. Mientras pueda, sé que un día ya no podré, pero mientras pueda... lo hago. [...] Es que si no me sentiría peor. Tu imagina, si yo me levanto, si tengo una mujer que me viene a limpiar, tú me dices "vale, qué bien” pero es que me sentiría peor, porque yo así pienso que... intento, que todavía puedo, sé que va a llegar un día que no, estoy mentalizada también ¿eh?” (EAF01).

Por otra parte, el que las mujeres afectadas de FM entrevistadas valoren su estado físico o definan su dolor a partir de la capacidad de desarrollar las tareas domésticas es igualmente revelador de cuán importantes son éstas para su identidad y autoestima.

"El dolor que yo llevaba en ese momento es donde estaba localizado el dolor al planchar" (EAF03).

Esto se relaciona con el sentimiento de realización personal que supone para estas mujeres, que en muchos casos se niegan a delegar en otros, como en los propios miembros de la familia, debido a que no quieren molestar pero también a que su espíritu perfeccionista les lleva a considerar que ellas lo harían mejor.

“[...] además mi marido a veces me dice “¡Pide! las cosas” pero yo soy una... como soy muy nerviosa antes de pedir, mientras que lo pido y me lo hacen... es 
peor, lavo yo y punto. Más rápido y mejor. Eso de toda la vida, que es que es un atraso mío" (EAF01).

Lo más llamativo es que estas mujeres, pese a estar enfermas y algunas incluso continuar trabajando, siguen asumiendo las tareas del hogar prácticamente en exclusiva -como el caso de una de las entrevistadas-, que una vez diagnosticada la enfermedad continuó con dos empleos diferentes por la mañana y por la tarde, limpiando su casa, levantándose a las 5 de la mañana y preparando la comida para todos de madrugada antes de irse al primer empleo y asumiendo en solitario el resto de tareas, pese a que su marido, sano, estuvo dos años en paro.

Un lugar común en las entrevistas de las afectadas de FM es el de la cocina. Se trata de una tarea, dentro de las responsabilidades familiares, feminizada en cuanto a que es desarrollada por las mujeres de la familia en calidad de "jefas del hogar" y sustentadoras de las vidas de los miembros de la familia. Las dificultades que encuentran para cocinar, por ejemplo a causa de los dolores, el cansancio o la debilidad, les generan sentimientos de inutilidad y frustración puesto que es por lo que han sido valoradas por los miembros de la familia., quizá por encima de otros aspectos de sus vidas.

Aún así, la limpieza es el aspecto del cuidado del hogar para el que las mujeres afectadas de FM encuentran mayor dificultad. El pronombre personal "me" resulta revelador de cómo estas mujeres conciben que la limpieza del hogar es su responsabilidad.

“[...] si llego y digo, ahora estos días, "tiéndeme la lavadora”, y me la tiende, me recoge la ropa, a lo mejor llega el domingo y no está en casa me hace la cama, pero cositas ¿sabes lo que te quiero decir?” (EAF01).

Por actividades concretas, a parte de la limpieza que incluye el barrer, fregar o asear las diferentes superficies, el hacer la colada -lavar, tender y planchar la ropa- es 
otra a las que las afectadas de FM entrevistadas hacen referencia, especialmente en cuanto a las consecuencias físicas que acarrean para ellas.

"La fregona, hay temporadas que la, yo los codos, eso de hacer así... que a mí el médico me ha dicho "la fregona nada" ¿sabes lo que te quiero decir? pero уо $[\ldots] "$ (EAF01).

Respecto a la ayuda de sus parejas, parece que sea algo opcional o tan inusual que las mujeres entrevistadas no hablan de ello, por lo que se hace necesario dirigir el discurso intencionadamente hacia este aspecto, de manera sutil preguntando por ejemplo, si siempre han asumido en solitario las tareas del hogar. Incluso es común que las afectadas de FM entrevistadas se autoconvenzan de la inconveniencia de pedir ayuda a sus maridos, debido a los argumentos que tradicionalmente han eximido a los varones de las responsabilidades domésticas: desarrollar la labor verdaderamente importante, el trabajo remunerado -en el espacio público-, por lo que cuando llegan a casa -el espacio privado- tienen la necesidad de descansar; así como su supuesta inaptitud para realizar labores domésticas consideradas femeninas y, por tanto, devaluadas.

"Si porque mi marido en casa hace muy poco. Es muy buena persona, es muy... yo no tengo queja de él en nada, en nada, porque fíjate si llevamos años casados y está siempre muy pendiente de mi, y siempre vamos juntos a todas partes, somos muy unidos los dos, lo que pasa es que es una persona más a la antigua usanza como digo yo, y que yo nunca le he insistido... porque yo tampoco le echo toda la culpa a él, porque sino también que la culpa es mía que desde el principio "No, es que tu tienes que fregar" desde el principio, a él no... él no, "te hace falta fregaplatos, pues fregaplatos, quieres esto, esto" si no tengo una mujer es porque no quiero yo, a ver si me entiendes... “¿qué pasa, te hace falta un fregaplatos? pues ten" de ahí lo que yo quiera, lo que yo quiera, de todo, lo que yo quiera, siempre "ponte una mujer que te ayude" y soy yo la 
que no quiero ¿sabes lo que te quiero decir? Ahora él en casa hace, es muy ordenado eso sí también te digo que lo dejan todo muy ordenado, ahora ayudar... lo justo. Quizá no saben, pero claro tampoco quieren como digo yo... Desde el principio, ahora ya tiene 60 años... [...] pero bueno yo a mi marido yo a veces digo "bueno y ahora este hombre con 60 años qué me va a hacer"... Pero no es como... cocinar no sabe, entonces él no se puede poner a cocinar" (EAF01).

Tan sólo una de las entrevistadas explicita cómo su marido, si bien no puede decirse que haya asumido en exclusiva las tareas del hogar, como sí es normal en las mujeres, ejerce una labor activa en ellas ofreciéndole un apoyo constante y liberándola de parte de la carga doméstica.

En cambio, la tónica dominante es que los maridos no colaboren en casa, lo que es asumido como algo normal por las mujeres entrevistadas y muy pocas le otorgan mayor importancia en su discurso. Y si les solicitan ayuda en este sentido, puede ser causa de conflicto puesto que para ellos su labor verdaderamente importante es el empleo remunerado y no consideran que sea responsabilidad suya la limpieza del hogar, sin percatarse que sus esposas también están cansadas debido a la enfermedad que sufren, uno de cuyos principales síntomas es la fatiga crónica.

Siguiendo con las tareas asignadas tradicionalmente a las mujeres y por las que son valoradas socialmente, las reuniones familiares, de las que ellas son anfitrionas y responsables de su organización, suponen para unas una pérdida de sus aptitudes e incluso puede suponer una situación de estrés añadido al tener que estar pendiente de todo. En relación con su salud, en concreto refieren estar peor tras celebrarse estas reuniones puesto que el esfuerzo les pasa factura a través del agotamiento físico y, con él, el dolor.

"Porque yo ahora mismo viene el domingo, vienen a comer, nos sentamos, somos 6, pues yo ese día ya el hacer la comida, que a mí me encanta la cocina, 
que no, porque hay personas, si es un suplicio hacer la comida estaría fatal, pero a mí me gusta mucho ¿no? Pero el hacer la comida, el tenerlo todo preparado, el... ese día yo estoy más nerviosa. Pues yo cuando llega que a lo mejor se van por la noche, tengo un cansancio encima... exagerao. Y a lo mejor no he hecho nada de la casa, que si empiezas "uy, a este le gusta esto, que si a este lo otro" y procuras hacerles cosas que les gusta a todos la comida, pones, aunque me ayuden a poner la mesa quitar la mesa y todo, yo ya me noto el cuerpo mmm... hasta como un poco de nerviosa, no sé cómo explicarlo. Me afecta. De todas formas te voy a decir una cosa, una cosa que me afecta mucho es ser nerviosa, el nervio ¿no? /.../ Y al ponerme nerviosa me noto más cansada ¿entiendes lo que te quiero decir? que a lo mejor el día que vienen ellos, que no limpio ni nada pero es... quiero tenerlo todo al día, tal, la comida, y cuando se van, me noto yo... rendida. ¿Sabes lo que te quiero decir? Y prácticamente tampoco es que haya hecho yo nada" (EAF01).

Otro aspecto que se ha intentado abordar, en relación a las responsabilidades familiares, es la vivencia y significados de la maternidad. En general, las mujeres tratan de desempeñar sus funciones de madre a costa de su tiempo libre y de su tiempo de ocio, sin exigirles a sus maridos la misma implicación. La mayoría de mujeres entrevistadas no tienen hijos pequeños, éstos ya se han independizado o son autosuficientes y por ello no describen esta relación en términos de presente sino de pasado, recordando la rutina diaria que caracterizaba su vida antes del advenimiento de la enfermedad. Además, estas mujeres se preocupan por el futuro de sus hijos desde el punto de vista de sentirse una carga para ellos, lo que les supone un factor añadido de preocupación y malestar.

"El cuidado de los niños también... eso mucho porque resulta que como mi marido era la empresa nuestra, trabajaba desde las 7 de la mañana hasta la 1 de la mañana, entonces yo tenía la educación... todo. Todo, todo, todo, todo era a 
mí... excepto los fines de semana pues que a lo mejor se iban con su padre. En este caso yo tampoco he sido de esas de "cuando venga tu padre verás", pues no... entonces... eh... yo he ido... y la disciplina, y todo eso lo tenía que poner yo. Todo todo todo, la educación, los estudios, la disciplina, todo lo he tenido que poner yo" (EAF02).

Cuidar a los demás ha sido y sigue siendo una actividad predominantemente realizada por mujeres, y sobre ellas recae la responsabilidad de cuidar a los nietos mientras sus hijas/os trabajan. Ante esta posibilidad, las entrevistadas son conscientes de que debido a padecer FM se encontrarían limitadas físicamente para ejercer esa labor de "ayuda" con sus hija/os y el no poder realizar esta actividad puede suponer para ellas una merma de su autoestima o sentimiento de utilidad, puesto que las mujeres son valoradas socialmente por su dedicación a los demás.

No obstante, las dos entrevistadas que ya tienen nietos se sienten aliviadas por no tener que hacerse cargo de sus nietos "gracias" a su enfermedad, por lo que ellas se ven autorizadas a hablar con libertad sobre otras "abuelas esclavas" que conocen en su entorno (Guijarro Morales, 2004). Cuidar a los nietos durante gran parte del día requiere una gran dosis de esfuerzo y dedicación, aunque muchas veces se pase por alto, esté mal visto socialmente el afirmarlo o, incluso, se piense que "a los abuelos les gusta estar con sus nietos" bajo cualquier circunstancia o que es lo "natural".

"Igual que lo de mi nieta, sé que no me la van a dejar pero es que yo no me encuentro capacitada para tenerla todo el día, yo eso de ahora coge a la nena, déjala ahí, y la comida, y que llora y que esto y... es que las martirizan ¿eh? [...] Y yo, ahora es que yo tengo una amiga que me dice " ¿y no te van a dejar a la nena todo el día?" y yo digo "si es que a mí me van a dar una alegría, porque es que yo no me encuentro bien" (EAF01). 


\subsection{El espacio público: la experiencia laboral de las mujeres afectadas de FM antes y después del diagnóstico de la enfermedad}

Las mujeres entrevistadas afectadas de FM se caracterizan por haber comenzado su vida laboral a edades tempranas y por haber ocupado puestos en el mercado laboral que pueden considerarse "duros": cansados físicamente y/o cansados en cuanto a intensidad y horario -como son los trabajos en fábricas de calzado que son característicos en las distintas poblaciones de la provincia de Alicante.

“[...] yo hacía 11-12 horas a destajo en una fábrica, que eso es pesaísimo, no sé si es porque he estado tan acostumbrada a trabajar o lo que sea que es como... como algo... natural, normal, no sé. Supongo que será que me he acostumbrado a eso, al cansancio. El cansancio para mi es lo normal, que para otra persona a lo mejor no es lo normal para mí sí lo es” (EAF03).

"Es que como trabajaba también en la hostelería [...] ha habido días que he podido trabajar, pues no sé qué decirte, 14-15-16 horas ¿sabes?” (EAF04).

"[...] cuando trabajaba de celadores, es un trabajo fácil pero muy pesado ¿entiendes lo que te quiero decir? porque tu si has estado en el hospital, el celador sabes que la, que el llevar camillas todo eso, a mi me afectaba y yo no decía nada, a ver si me entiendes, fue una época que mi marido estuvo en el paro, se quedó sin trabajo, entonces yo... a mí me afectaba pero tampoco decía nada" (EAF01).

Asimismo, en las historias de vida de las afectadas de FM es habitual encontrar que se hayan sucedido o incluso compaginado varios trabajos. Son mujeres trabajadoras, a las que les ha gustado trabajar fuera de casa porque lo han vivido como una liberación o se han sentido recompensadas con el sentimiento de autosuficiencia e independencia, lo que a su vez ha contribuido a aumentar su autoestima. 
Por ello, las vivencias de trabajar fuera de casa son a veces liberadoras para estas mujeres: el sentimiento de autorrealización potencia la autoestima y no se encasillan en la devaluación de las tareas domésticas. Todo ello reconociendo la sobrecarga que han tenido, como por ejemplo la reflexión de una de las entrevistadas sobre que el haber querido desenvolverse en el ámbito público, sin poder abandonar el privado, le ha acarreado una sobrecarga de trabajo.

"Sí, a mi trabajar me ha gustado. Es... a ver, a pesar de que a la larga parece que tenga perjuicios de haber trabajado y haber mantenido la casa, pero yo me, a mi me... yo he trabajado a parte de por necesidad porque me ha gustado [...] después he tenido que luchar como mujer y defiendo todas las cosas de las mujeres, que no soy una persona... vamos cuando me casé mi marido me dijo "pues tú te quedas en casa" y yo le dije "no", yo siempre tengo que trabajar, eso me ha hecho trabajar pues doble o triple ¿eh?” (EAF02).

Otras mujeres afectadas de FM también han tenido que abandonar su empleo, pero puesto que no es la faceta social por las que se las ha valorado tradicionalmente por encima de otras, este hecho no ha visto menoscabada su identidad o autovaloración, sino que el sentimiento de inutilidad por no poder cumplir los roles asignados a su sexo viene asociado a la incomprensión por parte de la familia, si estas mujeres no llevan a cabo o modifican su rutina de cuidado.

Cuando describen los trabajos que desempeñan, es característico que no sientan una separación radical entre el trabajo fuera del hogar y el propiamente doméstico, tal y como es usual que las mujeres ocupen aquellos cargos del mercado laboral relacionados con las tareas tradicionalmente femeninas, que a la vez coinciden con aquellos que exigen menor cualificación y que están peor remunerados.

En general, una proporción importante de las mujeres que trabajan fuera de casa realiza trabajos poco cualificados y, por tanto, es susceptible de vivir algunas de las características consideradas como potencialmente estresantes en el mundo laboral (y por 
tanto, negativas para la salud) como poca remuneración, escasa consideración social, pocas posibilidades de control y decisión sobre el trabajo, trabajos rígidos, poco creativos, monótonos, rutinarios, inferiores a la cualificación que posee la persona, ausencia de posibilidades de desarrollo personal y laboral (Valls, 1994; Ferrer Pérez, 1998). Porque la situación laboral de las mujeres se sigue definiendo por: segregación vertical (concentración en puestos de trabajo inferiores) y horizontal (concentración en una gama más estrecha de ocupaciones), techo de cristal (barreras invisibles que dificultan su promoción) y suelo pegajoso (cargas familiares que impiden su realización personal). Este tipo de trabajos, como es el de la limpieza, se caracteriza por exigir una serie de esfuerzos físicos en los que las afectadas de FM encuentran la mayor dificultad

Las mujeres afectadas de FM entrevistadas son mujeres luchadoras, que han trabajado desde jóvenes por obligación o por costumbre familiar. De una manera u otra, su infancia se ha visto trastocada, ya sea por un trauma emocional como el de la muerte de un progenitor o por tener que abandonar la vida infantil, en el colegio, e incorporarse al mundo laboral a edades tan tempranas como los 9 años.

“A los 9. Me fui a casa de una aparadora, a su casa, y estaba con ella, trabajando. Después, al año, cuando tenía 11 años, entré en una fábrica" (EAF02)

"Bueno, con 7 años tenía mi padre el bar y ya estaba también ayudándolo. Con 10 años ya estaba en una fábrica de calzado y ayudando" (EAF03).

“[...] yo a los 14 años me puse a currar, o sea soy una machaca, un burrico de carga $[\ldots] "$ (EAF04).

Es habitual entre ellas el referir haber tenido que dejar los estudios prematuramente, lo que les ha supuesto una frustración al no poder cumplir sus deseos de autorrealización personal. En ocasiones, han tenido que dejar atrás aspiraciones personales en pro del cuidado de la familia. Han antepuesto las aspiraciones de los demás a las suyas, como las aspiraciones laborales de los maridos o, simplemente, el 
cuidado y tiempo de los hijos. Si han intentado llevarlo todo, ha sido en perjuicio de su salud y han tenido que acabar escogiendo prioridades.

"De sentir que no llegaba a todo, claro. Cuando hice el acceso [a la Universidad] si yo me hubiese encontrado bien hubiese seguido estudiando, pero yo veía que no podía, que no llegaba, entonces yo digo: antes de cogerme una... depresión o un agobio prefiero dejarlo" (EAF02).

Sobre todo, en los discursos de las mujeres entrevistadas se refleja la doble jornada en el empleo y en el hogar, un fenómeno que afecta prácticamente en exclusiva a las mujeres y del que ellas no son conscientes como tal, no tienen un nombre para ello, pero sí es una constante al describir rutina diaria presente o pasada.

"Yo era aparadora, y entonces cuando nos casamos, cuando iba a tener a este chico que tiene ahora 27 años, mi marido puso una empresa. Y... puso una empresa, y siempre he estado ayudándole, mis hijos... con mi marido, siempre ayudándole /.../ y entonces cuando él puso la empresa, yo primero le ayudaba a aparar, le ayudaba a aparar, pero luego después llevaba a la gente, llevaba a la gente y ayudaba a aparar, las dos cosas. Y en casa. Y los hijos” (EAF02).

Aunque llegan a reconocer que se han sentido estresadas durante sus vidas, parece que no hayan reflexionado sobre ello porque han asumido la sobrecarga de responsabilidades, derivada de la doble jornada en el empleo y en el hogar, como algo normal, a lo que se suma su afán de perfeccionismo y de desvivirse por el cuidado de los demás: el "ser para otros" que define el ideal de mujer y la identidad femenina (Lagarde y de los Ríos, 1997) y que puede generar malestar al ser interiorizado rígidamente por las mujeres, en especial en este caso por las afectadas de FM. 
“Sí, épocas de estrés sí que he pasado, porque ya te digo si iba a trabajar y quieras o no quieras... y luego lo de la casa, yo siempre he sido una persona, no sé cómo decirte, que me ha gustao que fueran bien y que lo tuvieran todo hecho, y sigo igual ¿eh? Porque muchas veces eh... están mis hijos “ay mamá”, yo soy así, y si eres así no puedes cambiar. Intentas, intentas cambiar pero no puedes. Yo todo, y he intentao, si me he tenido que acostar tarde por plancharles, por hacerles esto, por dejarles la comida, por dejarlo todo arreglao, todo solucionao pa todos y siempre he sido así. O sea épocas de estrés he pasao por el trabajo" (EAF01).

Ellas mismas reconocen que la sobrecarga, el exceso de trabajo del tipo que sea, es perjudicial para su estado físico. Aunque no les gusta depender de los demás e intentan sobrellevar su ritmo de trabajo con la misma intensidad que antes, llega un momento en el que son conscientes que necesitan ayuda y tienen que pedir ayuda, aunque esto lo vean como una resignación. Y, como consecuencia, ven sus propias limitaciones como una desventaja a la hora de compararse con otros trabajadores, lo que también les genera un sentimiento de inseguridad en este terreno.

\section{Reflexiones finales}

La FM se ha estudiado, sobre todo, desde la perspectiva biologicista y clínica, emergiendo recientemente la necesidad de concebir el proceso de salud-enfermedad desde un modelo biopsicosocial, en el que también se tenga en cuenta el contexto social en el que las personas desarrollan sus experiencia vital.

En este estudio piloto se ha pretendido ofrecer una primera aproximación a las experiencias vitales de las afectadas de FM, sobre todo en cuanto al desarrollo de las tareas del hogar y el desempeño de un empleo remunerado, y las consecuencias sobre la calidad de vida que acarrea sufrir una enfermedad tan limitadora como la FM. Se ha 
tenido en cuenta por encima de otros factores las dificultades que han encontrado las mujeres afectadas de FM a la hora de conciliar la vida laboral y familiar.

Considerando los resultados expuestos, se percibe que persiste una desigualdad de roles dentro de los hogares de las mujeres afectadas de FM. Las tareas del hogar se han revelado para estas mujeres como una obligación, si bien tan interiorizada y asumida hasta tal punto que no es cuestionada, sí generadora de un grado de sobrecarga que genera malestar. Y es que la interiorización de la identidad femenina y el mandato de género, del “deber ser mujer", es tan sutil que ni las propias afectadas son conscientes.

Si bien puede considerarse que las mujeres, en general, contribuyen a perpetuar estos modelos sexistas, no son por ello culpables pues la socialización de género las hace prisioneras de ellos; se trata de una violencia estructural que se aferra a la ideología, se aprehende día a día y cuesta mucho esfuerzo desprenderse del molde cultural que se ha impuesto.

El contexto social en el que se inscriben las experiencias relatadas por las mujeres entrevistadas coincide con el de la sociedad española actual en la que, a pesar del ideal igualitario que se refleja en hechos sociales como la incorporación progresiva de las mujeres al mercado de trabajo, la transposición de roles no ha sido bidireccional. Y es que la situación social ha cambiado a un ritmo más rápido que la ideología, pues aún persisten prejuicios y mitos sexistas en el imaginario colectivo, lo que determina que muchos hombres y también mujeres se adscriban al rígido modelo de género que otorga roles diferenciados a cada sexo.

En este contexto de cambio, las mujeres tienen un papel muy importante en la aportación de nuevos valores, así como en la transformación de los antiguos tanto para hombres como para mujeres. Pero, en el contexto de la vida en pareja, la realidad es que el trabajo y los ingresos de las mujeres no producen una modificación de los roles en el seno de la pareja. Y, todo ello, de una manera u otra, tiene su impronta en la salud de las mujeres. 


\section{BIBLIOGRAFÍA}

- Aparicio, D. (2002): "Fibromialgia: viejas y nuevas dolencias". En La salud de las mujeres. IV Jornadas de la Red de Mujeres Profesionales de la Salud, Madrid, 25 de octubre de 2002. Madrid: Ministerio de Trabajo y Asuntos Sociales-Instituto de la Mujer $\mathrm{n}^{\mathrm{o}} .29$, pp. 101-105.

- Blanco, P.; Ruiz Jarabo, C.; García de Vinuesa, L. y Martín García, M. (2004): “La violencia de pareja y la salud de las mujeres". En Gaceta Sanitaria, vol. 18, supl. 1, pp.182-8.

- Burin, M.; Moncarz, E. y Velázquez, S. (1990): El malestar de las mujeres. La tranquilidad recetada. Buenos Aires: Paidós.

- Cantera Espinosa, L. (2004): "Más allá del género. Nuevos enfoques y "nuevas" dimensiones y direcciones de la violencia en la pareja”. En Athenea Digital, no.6.

- Carbonell Abelló, J. (2005): “Fibromialgia". En Medicina Clínica, vol. 125, n. 20, pp. 778-9.

- Collado, A. et al. (2002): "Documento de consenso sobre el diagnóstico y tratamiento de la Fibromialgia en Cataluña”. En Medicina Cliníca (Barcelona), vol. 118, pp.745-9.

- Escribà Agüir, V. (1997): “Trabajar fuera de casa. ¿Mejora la salud de las mujeres?”. En Medicina Clínica (Barcelona), vol. 108, pp. 580-581.

- Esteban, Ma L. (2006): "El estudio de la salud y el género: las ventajas de un enfoque antropológico y feminista”. En Salud Colectiva, vol. 2, nº. 1, pp.9-20.

- Fernández E.; Schiaffino A. y Martí M. (2000): “Influencia del trabajo doméstico sobre la salud y la utilización de servicios sanitarios en mujeres con trabajo remunerado y amas de casa”. En Gaceta Sanitaria, vol. 14, nº. 4, pp. 287-290.

- Ferrer Pérez, V. A.; Bosch Fiol, E. y Gili Planas, M. (1998): “Aspectos diferenciales en salud entre las mujeres que trabajan fuera del hogar y las amas de casa". En Psicothema, Vol. 10, nº. 1, pp. 53-63.

- García Calvente, Ma. M.; Mateo Rodríguez, I. y Maroto Navarro, G. (2004): “El impacto de cuidar y la calidad de vida de las mujeres". En Gaceta Sanitaria, vol.18, 
supl. 2, pp. 83-92.

- Gómez Ortiz, V. (2004): “Estrés y salud en mujeres que desempeñan múltiples roles”. En Avances en Psicología Latinoamericana, vol. 22, pp.117-128.

- González de Chávez, A. (2002): “La Fibromialgia. Su relación con la condición de las mujeres". En Seminario Balance y perspectivas de los estudios de las mujeres y del género. Madrid: Ministerio de Trabajo y Asuntos Sociales-Instituto de la mujer, $\mathrm{n}^{\mathrm{o}} .40$, pp.277-292.

- Guijarro Morales, A. (2004): El síndrome de la abuela esclava. Pandemia del siglo XXI. $2^{a}$ ed., Granada: Grupo Editorial Universitario.

- Lagarde y de los Ríos, M. (1997): Los cautiverios de las mujeres: madresposas, monjas, putas, presas y locas. México: UNAM.

- Martínez Benlloch, I. (2003): "Los efectos de las asimetrías de género en la salud de las mujeres”. En Anuario de Psicología, vol. 34, n. 2, pp. 253-266.

- Mingote Adán, C. (2000): "Medicina psicosomática desde la perspectiva de género". En II Jornadas de Salud Mental y Género. Madrid, 9 y 10 de octubre de 2000. Madrid: Ministerio de Trabajo y Asuntos Sociales- Instituto de la Mujer nº 32.

- Muro Gastañaga, J. (2007): “Algunas reflexiones en torno a la Fibromialgia”. En Revista de Psicoanálisis de la Asociación Psicoanalítica De Madrid, nº. 52, pp.105127.

- Paterna Bleda, C. y Martínez Martínez, Ma . C. (2003a): “Comprender la fibromialgia desde una perspectiva psicosocial feminista". En Encuentros de Psicología Social, vol. $1, n^{\circ} .4$, pp. $100-104$.

- Paterna Bleda, C. et al. (2003b): "Aspectos psicosociales de la fibromialgia: una perspectiva de género". En Revista de Psicología Social Aplicada, vol. 13, nº 1, pp. 9111.

- Pérez Pareja, J. et al. (2004): "Fibromialgia y emociones negativas". En Psicothema, vol. $16, \mathrm{n}^{\mathrm{o}} .3, \mathrm{pp} .415-420$.

- Rivera, J. et al. (2006): "Documento de consenso de la Sociedad Española de Reumatología sobre la fibromialgia”. En Reumatología Clínica, no. 2, Supl. 1, pp.55-66. 
- Ruiz Pérez, I. et al. (2008): "Risk factors for fibromyalgia: the role of violence against women”. En Clinical Rheumatology, nº. 28, pp. 777-786.

- Ruiz Pérez, I. et al. (2007): “Diferencias en características sociodemográficas, clínicas y psicológicas entre hombres y mujeres diagnosticados de fibromialgia”. En Revista Clínica Española, vol. 207, nº. 9, pp. 433-9.

- Sánchez López, Ma. P.; Dresch, V. y Cardenal Hernáez, V. (2005): "Relaciones entre salud física y psicológica en mujeres de mediana edad”. En Psicología, vol. XIX, nº 12, pp. 107-136.

- Tosal Herrero, B. (2007): "Síndromes en femenino. El discurso biomédico sobre la fibromialgia”. En Feminismo/s, nº. 10, pp. 79-9.

. (2008): "El cuerpo como excusa. El diagnostico de la fibromialgia en una consulta de reumatología". En Index de Enfermería, vol. 17, n. 1, pp. 12-16.

- Ubago Linares, $\mathrm{M}^{\mathrm{a}}$ C. et al. (2005): “Características clínicas y psicosociales de personas con fibromialgia. Repercusión del diagnóstico sobre sus actividades". En Revista Española de Salud Pública, año/vol. 79, nº. 006, pp. 683-695.

- Valls-Llobet, C. (1994): Mujeres y hombres, salud y diferencias. Barcelona: Folio. (2002): "El dolor de las mujeres: diagnóstico diferencial", La salud de las mujeres. En IV Jornadas de la Red de Mujeres Profesionales de la Salud, Madrid, 25 de octubre de 2002. Madrid: Ministerio de Trabajo y Asuntos Sociales- Instituto de la Mujer no. 29, pp. 49-63.

. (2006): Mujeres invisibles. Barcelona: De Bolsillo $\mathrm{n}^{\circ} .162$. (2007): "Diagnóstico diferencial del dolor y de la fibromialgia”. En Anuario de Psicología, vol. 39, nº 1, pp. 87-92.

- Velasco, S.; Ruiz, M.T. y Álvarez-Dardet, C. (2006): “Modelos de atención a los síntomas somáticos sin causa orgánica. De los trastornos fisiopatológicos al malestar de las mujeres”. En Revista Española de Salud Pública, vol. 80, nº 04, pp.317-322.

- Wolfe, F., et al. (1990): “The American College of Rheumatology 1990 criteria for the classification of fibromyalgia: report of the Multicenter Criteria Committee". En Artritis \& Rheumathism, vol. 33, pp.160-72. 